\title{
EPMA and Quantitative EDS of Rare Earth Elements in Geochronological Reference Materials
}

Heather A. Lowers ${ }^{1}$, David T. Adams ${ }^{1}$ and Nicholas W.M. Ritchie ${ }^{2}$.

${ }^{1 .}$ Central Minerals and Environmental Resources Science Center, U.S. Geological Survey, Denver, CO USA

${ }^{2 \cdot}$ Microscopy and Microanalysis Research Group, NIST, Gaithersburg, MD

Microanalysis of rare earth elements (REE) in geologic materials is traditionally done with electron microprobes with wavelength dispersive spectrometers (EPMA) with software algorithms to correct for peak interferences and choice of background models because of its superior spectral resolution and detection limits [1]. However, the number of elements that require standardization, often more than 20, and required counts times to achieve desired detection limits may result in analysis times of 15 minutes or more per analysis spot. Scanning electron microscopy with energy dispersive spectroscopy (SEMEDS) may provide faster acquisition times as all elements are analyzed simultaneously and peak interferences are deconvoluted using linear least squares modeling. REE concentrations in geochronological reference materials, monazite (NAM) and xenotime (BS-1) determined using EPMA, SEM-EDS, and solution ICP-MS [2] are compared to asses the accuracy and precision of quantitative EDS and suitability of these materials as microanalytical reference materials.

EPMA data were collected on a JEOL 8900 operated at $20 \mathrm{kV}, 50 \mathrm{nA}, 10 \mathrm{um}$ spot, and $60 \mathrm{~s}$ on peak and background at USGS. Smithsonian Institution REE orthophosphate standards were used as primary reference materials. Interference corrections and background modeling was handled with Probe for EPMA. Multiple spots on multigrain grains of NAM (10 spots on 9 grains) and BS-1 (10 each on 17 grains) were collected. SEM-EDS data were collected on a TESCAN MIRA3 operated at $20 \mathrm{keV}$ and $\sim 0.9 \mathrm{nA}$ beam current with $4 \times 30 \mathrm{~mm}^{2}$ PulseTor silicon drift detectors at NIST. The data was all collected under automation using the SEMantics instrument control software extension to NIST DTSAII $[3,4]$. The probe current was remeasured after each $300 \mathrm{~s}$ interval. The spectra from the 4 independent SDDs were combined into a single spectrum for quantification.

Standards were collected from an SPI Rare Earth Phosphate standard block containing 15 REE pentaphosphates (XP5O14 where $\mathrm{X}=\mathrm{REE}$ ). Mass fractions were calculated from stoichiometry and nominal atomic masses. Five replicates of each standard were collected for $60 \mathrm{~s}$ each. The five replicates were combined into a single $300 \mathrm{~s}$ standard spectra except in cases in which the spectrum from one or more replicates was clearly different. In this case, the different spectrum was removed and the remaining spectra combined. The spectra were combined with any necessary references into standard bundles for use in quantification. The most common reference requirement was due to the interference of the X M-lines with the P K lines with GdP5O14 serving as the P K reference. The X Mline reference was often created from the standard by trimming out the $\mathrm{P} K$ line. Since we were not using the X M-lines in the quantification and since we had a clean $\mathrm{P} \mathrm{K}$ reference, this procedure proved adequate although it did leave some structure in the residual around the $\mathrm{P} \mathrm{K}$ peak. Additional standards were required for $\mathrm{Si}$ (pure $\mathrm{Si}$ ), $\mathrm{Al}$ (pure $\mathrm{Al}$ ), $\mathrm{Ca}(\mathrm{CaF} 2)$ and $\mathrm{As}$ (pure As). Ten spectra from one grain each of the materials NAM and BS-1 were collected at $20 \mathrm{keV}$ for $600 \mathrm{~s}$ each. 
Results of the analyses are reported in Table 1. The EPMA detection limit for most elements was $~ 300$ ppm with the exception of Ho which was $900 \mathrm{ppm}$. Similar detection limits were determined for SEMEDS based on the elements reported. There is general agreement among the three methods but no two methods consistently agree with one another. The smallest relative standard deviation was observed from the SEM-EDS data for both the NAM and BS1 materials. This implies the material may be homogenous on the individual grain scale $(<500 \mathrm{um})$ but bulk values cannot be assumed for all distributed grains.

\section{References:}

[1] H. A. Lowers and P. K. Carpenter, Microscopy and Microanalysis 21 (2015), p. 1881.

[2] J. A. Aleinikoff et al, American Journal of Science 312 (2012), p. 723.

[3] N.W.M Ritchie and V. Filip, Microscopy and Microanalysis 17 (2011), p. 896.

[4] DTSAII D. E. Newbury and N. W. Ritchie, Journal of Materials Science 50 (2015), p. 493.

Table 1. REE concentrations (in parts per million) in NAM and BS-1 determined using solution ICPMS [2], EPMA, and SEM-EDS. The numbers in parentheses represent the relative percent of two standard deviations. bdl=below detection limit, $\mathrm{nr}=$ not reported

\begin{tabular}{|c|c|c|c|c|c|c|}
\hline Material & \multicolumn{3}{|c|}{ NAM } & \multicolumn{3}{c|}{ BS1 } \\
\hline Element & ICP-MS & EPMA (n=88) & $\begin{array}{c}\text { SEM-EDS } \\
(\mathrm{n}=10)\end{array}$ & ICP-MS & EPMA (n=168) & $\begin{array}{c}\text { SEM-EDS } \\
(\mathrm{n}=10)\end{array}$ \\
\hline $\mathrm{La}$ & $75470(10.5)$ & $82688(1.95)$ & $79381(1.14)$ & $5.12(10.4)$ & $\mathrm{bdl}$ & $\mathrm{nr}$ \\
\hline $\mathrm{Ce}$ & $199400(9.01)$ & $213464(1.09)$ & $204248(0.25)$ & $116(19.2)$ & $\mathrm{bdl}$ & $\mathrm{nr}$ \\
\hline $\mathrm{Pr}$ & $24544(18.5)$ & $28903(32.9)$ & $26713(2.31)$ & $82.2(20.9)$ & $\mathrm{bdl}$ & $\mathrm{nr}$ \\
\hline $\mathrm{Nd}$ & $90346(11.2)$ & $95328(1.76)$ & $95837(0.53)$ & $1694(29.0)$ & $1635(48.5)$ & $1200(17.8)$ \\
\hline $\mathrm{Sm}$ & $29799(10.9)$ & $29210(4.95)$ & $32425(1.92)$ & $5684(15.9)$ & $6509(46.9)$ & $4196(12.6)$ \\
\hline $\mathrm{Eu}$ & $57.7(11.7)$ & $\mathrm{bdl}$ & $\mathrm{nr}$ & $2313(18.4)$ & $1978(41.9)$ & $1981(13.6)$ \\
\hline $\mathrm{Gd}$ & $21530(12.1)$ & $22208(6.89)$ & $22061(1.40)$ & $28646(24.3)$ & $30504(26.3)$ & $25642(6.54)$ \\
\hline $\mathrm{Tb}$ & $2510(20.7)$ & $\mathrm{bdl}$ & $4279(6.82)$ & $7474(22.2)$ & $6694(17.6)$ & $7344(7.60)$ \\
\hline $\mathrm{Dy}$ & $8863(9.37)$ & $6149(8.58)$ & $9499(3.94)$ & $56624(28.3)$ & $54619(8.45)$ & $57249(1.79)$ \\
\hline $\mathrm{Ho}$ & $795(20.4)$ & $\mathrm{bdl}$ & $\mathrm{nr}$ & $11805(30.5)$ & $12091(13.6)$ & $10103(16.2)$ \\
\hline $\mathrm{Er}$ & $1359(20.1)$ & $1385(22.0)$ & $1996(32.3)$ & $32739(27.0)$ & $31723(6.57)$ & $34945(2.55)$ \\
\hline $\mathrm{Tm}$ & $107(26.7)$ & $358(95.6)$ & $\mathrm{nr}$ & $4331(28.4)$ & $4254(11.7)$ & $4403(11.1)$ \\
\hline $\mathrm{Yb}$ & $491(18.1)$ & $\mathrm{bdl}$ & $\mathrm{nr}$ & $22234(28.4)$ & $20076(13.6)$ & $21298(4.34)$ \\
\hline $\mathrm{Lu}$ & $45.1(38.3)$ & $340(87.6)$ & $\mathrm{nr}$ & $2274(21.5)$ & $1913(34.7)$ & $194(601)$ \\
\hline
\end{tabular}

